\title{
El nuevo proceso de canonización de la edad moderna
}

The new canonization process of the modern age

\section{Giulio SODANO}

Dipartimento di Lettere e Beni culturali

Università degli Studi della Campania «Luigi Vanvitelli»

https://orcid.org/0000-0001-6928-8127

giulio.sodano@unicampania.it
Resumen: La canonización en la edad moderna se transforma en una operación jurídica compleja y burocratizada, en la cual el factor tiempo asume un papel determinante para no tomar decisiones apresuradas. Una causa de beatificación y de canonización comprendía varios procesos y se dividía en dos fases: la primera se desarrollaba en los tribunales locales, en la localidad en que la fama de santidad había surgido y desde la que se había difundido, mientras que la segunda era competencia del pontífice y tenía lugar en la Sagrada Congregación de Ritos. Las novedades «modernas» de procedimiento que influyeron fuertemente en los contenidos de los procesos son dos: la acuñación de la fórmula de las virtudes heroicas y los decretos de Urbano VIII con el nacimiento del proceso sobre el no culto. Estos permitieron poner en marcha un mecanismo para seleccionar los modelos de santidad más adecuados a las necesidades de la Iglesia.

Palabras clave: canonización, santidad, proceso, virtudes heroicas. virtues.

\section{SANTIDAD Y PROCEDIMIENTO AL INICIO DE LA EDAD MODERNA}

El primer cuento del Decameron de Boccaccio narra la historia de Ser Ciappelleto, un pecador impenitente que encontrándose en el final de su vida en Borgoña se confiesa con un ingenuo fraile, contándole una vida tan inmaculada que le induce a pensar que estaba delante de un santo. Una vez muerte, el fraile va difundiendo sus admirables virtudes hasta el punto de que a su funeral acude una gran multitud que trata de hacerse con sus reliquias, arrancándole el vestido: $\ll Y$ mientras tanto crecía la fama de santidad y devoción en torno a su figura, hasta el punto de 
que todos, en cualquier adversidad, se dirigían a él antes que a otro santo, y lo llamaron y aún siguen llamándolo san Ciappelleto: y afirma que ha obrado muchos milagros que Dios ha realizado a través de él».

La satírica representación de Boccaccio de una proclamación de la santidad no era, en realidad, un evento fuera de lo común en el Europa medieval. Se llegaba a ser santo, sobre todo, a través de la difusión de la fama sanctitatis, que nacía de un modo espontáneo entre los entusiastas devotos. De alguna manera, la situación de la muchedumbre que en la plaza de san Pedro en los funerales de Juan Pablo II ha pedido con grades voces «santo subito» se asemeja en gran medida al procedimiento medieval basado en la fama pública antes que en el largo recorrido jurídico propio de la edad moderna.

El nacimiento del proceso de canonización de la época de la reforma gregoriana hasta el umbral de los tiempos modernos ha sido magistralmente reconstruido por el poderoso trabajo de André Vauchez ${ }^{1}$. El proceso medieval, sin embargo, aun dando un prestigio mayor al santo que venía canonizado a través de un acto pontificio, no era el único camino a través del cual se alcanzaba la gloria de los altares, porque la vía episcopal quedaba siempre abierta como un recorrido «alternativo», que no negaba el consecución de la bienaventuranza. También, desde el punto de vista de la modalidad para el reconocimiento de la santidad, el tardo medievo fue pluralista. Es cierto que ya Inocencio III había conseguido la reserva pontificia sobre la canonización en el año 1200 con motivo de la proclamación de santa Cunegunda ${ }^{2}$, pero la tendencia a seguir confiando a los obispos una amplia autoridad en materia de santidad continuaron siendo fuertes. $\mathrm{Al}$ menos hasta el siglo XVI y sobre todo hasta los decretos urbanianos, de los que hablaré, en el occidente católico persistió una pluralidad grande de grados de santidad, dependiendo de la autoridad que atribuía el título: los beatos reconocidos por los obispos a los cuáles venía prevalentemente atribuido un culto local; los santos canonizados por el papa; los beatos (realmente pocos) proclamados como tal por el pontífice, a los cuales se les otorgaba también un culto local.

La novedad de la santidad en la edad moderna estuvo en hecho de que el papado asumió el monopolio absoluto de la «selección» de los santos a través de un renovado procedimiento procesual. Ha sido dicho que la santidad es la dimensión

1 André VAUCHEZ, La santità nel Medioevo, ed. it., Bologna, 1989 (2009). Se recuerda que la primera canonización históricamente documentada es la del obispo de Augsburgo, Udalrico en el 993. Cfr. IVI. pp. 33-34.

2 Véase a este propósito Stephan KuTTNer, La réserve papale du droit de canonisation, en Revue historique de droit français et étranger, XVIII (1938), pp. 172-228. 
que revela mayormente la dialéctica entre el impulso de la Iglesia y la inclinación a la religiosidad propia de las poblaciones. A través de esta dialéctica los pontífices no han impuesto a los santos, sino que los han seleccionado ${ }^{3}$. El proceso de canonización moderno ha sido un instrumento a través del cual la Iglesia ha elegido los modelos de santidad que mejor responden a las exigencias del propio tiempo ${ }^{4}$.

La afirmación del monopolio pontificio fue gradual y no siempre siguió un recorrido lineal. Seguramente, no obstante, contribuyó a su afirmación la profunda crisis que la figura del santo había sufrido antes del Concilio de Trento. La citada novela de Boccaccio, así como otros tantos ejemplos literarios tardo medievales, eran una expresión satírica de la gran corrupción que circundaba el culto de los santos, sobre todo a nivel local, corrupción que había profundamente impresionado a Lutero en su viaje a Roma. Las últimas canonizaciones habían sido las de san Bruno en el 1514, de san Francisco de Paula en el 1519, de san Antonino de Florencia y de san Benón de Meissen en el 1523. Pero, a consecuencia de las críticas sobre la santidad de parte de protestantes como de reformadores católicos ${ }^{5}$ -precisamente la canonización de san Benón fue ocasión para que Lutero escribiese un libelo contra el culto a los santos-, la actividad de lo que ha sido denominado la «fabrica» de los santos tuvo un prolongado parón, que era signo de que una fase de reflexión se había abierto en el ámbito de la jerarquía católica sobre este tema tan delicado. Que no era tiempo de «fáciles» santos se percibe por el retroceso del fenómeno denominado de las «santas vivas» que había caracterizado a la Italia centro-septentrional, que tratándose de un fenómeno muy difundido entre finales del siglo XV y los primeros años del siglo XVI, acabó desapareciendo ${ }^{6}$. Aquella santidad de tonos apocalípticos y proféticos, con la petición de una reformatio in capite et in membris no se adaptaba con el cambiado clima de los años treinta del siglo XVI, con las altas jerarquías eclesiásticas siempre más orientadas a retomar un férreo control de los fieles. En los ambientes reformistas católicos se había di-

3 Giuseppe GaLASSO, L'altra Europa. Per un'antropologia storica del Mezzogiorno d'Italia, Milano, 1982, pp. 79-82.

4 Giuseppe Dalla TORRE, Processo canonico (processo di beatificazione e canonizzazione), en Enciclopedia del diritto, Milano, 1987, p. 943.

5 Jean Delumeau, La sainteté catolique, in Histoire des saints et de la sainteté chrétienne, vol. VIII, Paris, 1987, pp. 25-35, p. 27; Jean DELUMEAU, Rassurer et protéger. Le sentiment de sécurité dans l'Occident d'autrefois, Paris, 1989, p. 183. Veáse también, Simon DITCHFIELD, How not to be a Counter-reformation saint: the attempted canonization of Pope Gregory X, 1622-1645, en Papers of the British School at Rome, LX (1992), p. 379; Jean Michael SALLMANN, Santi barocchi: modelli di santità, pratiche devozionali e comportamenti religiosi nel Regno di Napoli dal 1540 al 1750, Lecce, 1996, p. 123 y ss.

6 Gabriella ZARRI, Le sante vive. Profezie di corte e devozione femminile tra '400 e '500, Torino, 1990. 
fundido la convicción de que el culto a las reliquias y a los santos, por su carácter próximo a la superstición, podía ser dejado al pueblo ignorante, mientras que las élites podían prescindir de él. También aquí, a medida que se fueron afirmando las líneas más rigoristas, la aproximación intelectual de la élite a la vida devocional fue vista con sospecha, mientras que se reafirmaba con fuerza el contenido único de las prácticas de la vida religiosa, a la cuales todos necesariamente debían participar ${ }^{7}$.

En el Concilio de Trento, el argumento de la santidad fue tratado de modo muy sumario en la sesión XXV, entre el 2 y el 4 de diciembre de 1563. Aquella sesión, como es bien conocido, construyó una verdadera muralla frente a las tesis de los reformadores protestantes, reafirmando con fuerza, contra toda tendencia iconoclasta, la validez del recurso a las imágenes devotas y a la intercesión de los santos $^{8}$. Fue, por tanto, afirmado de un modo solemne que Cristo era el único redentor y salvador de la humanidad, pero también se reafirmó que, como enseñaba la tradición, la invocación de los santos era una cosa buena y útil, en la medida en que estos habían sido considerados como intercesores. Pablo Sarpi en su Historia del Concilio tridentino, narra cómo justo después de la aprobación de la doctrina de las ánimas del purgatorio, se pasó a ordenar «a los obispos y a todos los que tienen la misión de enseñar, la obligación de instruir al pueblo sobre la intercesión y la invocación a los santos, el honor tributado a las reliquias y el legítimo uso de las imágenes según la antigua doctrina de la Iglesia, con el consenso de los padres y de los decretos conciliares; enseñando que los santos rezaban por los hombres y que es útil invocarles y recurrir a sus oraciones y a su ayuda». Por todo esto, caían bajo la condena de la Iglesia todas las proposiciones protestantes que había negado el culto a los santos. Sobre las imágenes, algunos pasajes insistían con más fuerza sobre los aspectos disciplinares, invocando, al menos, la necesidad de consultar a la más alta autoridad: «sea quitada toda superstición en la invocación de los santos, veneración de las reliquias y uso de las imágenes [...] que en ninguna iglesia o en otro lugar hay ninguna imagen inusual si no está aprobada por el obispo, ni sean admitidos nuevos milagros o recibidas nuevas reliquias». En casos particulares de «dificultades graves» no sea decretada cosa alguna nueva o extraordinaria en la iglesia sin el parecer del papa»`. Aun acreditando un papel relevante a los obispos en la gestión de las reliquias y de las imágenes, en Trento se insistía sobre la importancia del parecer del papa al menos en lo que respecta a las cosas «nuevas» 0 «inusuales».

7 Adriano ProsPeri, Intellettuali e Chiesa all'inizio dell'età moderna, en Corrado VIVANTI (ed.), Annali della Storia d'Italia, vol. IV, Intellettuali e Potere, Torino, 1981, pp. 159-252.

8 IDEM, Il Concilio di Trento: una introduzione storica, Torino, Einaudi, 2001, p. 87.

9 Paolo SARPI, Istoria del concilio tridentino, ed. Sansoni, Firenze, 1966, vol. II, pp. 1028-1029. 


\section{INCERTEZA Y REPRESIÓN DESPUÉS DE TRENTO}

El culto de los santos indudablemente resulta para la Iglesia católica un instrumento muy relevante para recuperar a los fieles perdidos después del cisma protestante y por este motivo, en Trento, la santidad fue defendida plenamente en el plano doctrinal, pero también desde ese momento se desplegaron los mecanismos encaminados a establecer un cuidadoso control y, sobre todo, a la selección de sus modelos, realizando un diseño de control papal sobre las «novedades y cosas insólitas». De todo esto se puede deducir que surgen dos filones de intervenciones, que caracterizan la santidad en la edad moderna: por un lado, la revisión crítica de todas las vidas antiguas de los santos antiguos, operación que puso en primera línea a los bolandistas; por otro lado, en lo atañía a los «nuevos» santos, una reorganización del aparato procedimental del proceso de beatificación y canonización, con la consecuente reorganización de los criterios para el reconocimiento de la santidad. Sobre el primer punto, la hagiografía intentó dar una solución al problema de los santos antiguos, con la intervención de Lippomano y Surio, autores de sendas recopilaciones de vidas de santos. La obra de Surio anticipó la Acta Sanctorum proyectada por el jesuita Roberto Resweyde a partir del 1607 y cuyos volúmenes empezaron a aparecer en 1643. El Martyrologio Romano fue compilado por el cardenal Sirleto, siguiendo el encargo de Gregorio XIII y con la colaboración de Cesar Baronio ${ }^{10}$.

Si la hagiografía buscaba resolver con sus reglas los problemas de los «santos antiguos», faltaba por afrontar el problema de los «nuevos santos», que en gran número llamaban a la puerta de la santidad. El clima controreformista con el nacimiento de las nuevas congregaciones religiosas deseosas de conseguir para sus propios componentes un puesto digno sobre los altares de una catolicidad que se quería mostrar triunfante, imponía, de hecho, un crecimiento exponencial de la santidad canonizada. Las presiones eran fuertes para la canonización de los padres fundadores de la Compañía de Jesús -Ignacio de Loyola y Francisco Javier- al igual que para Carlos Borromeo o para otros exponentes de la que será llamada la reforma católica.

El post Trento representó una fase de transición en la cual los procedimientos de canonización fueron gestionados, de alguna manera, por el tribunal de la Inquisición, antes de que la fundación de la Sagrada Congregación de Ritos (1588) pusiera en marcha la definición precisa de un itinerario para el proceso de canonización. Entre el 1523 y el 1588 no hubo nuevas canonizaciones, aunque

10 Hugo LÄMMER, De Martyrologio Romano, Ratisbona, 1878. 
el procedimiento para el reconocimiento de los cultos locales siguió existiendo, al menos en parte, hasta que no fue completamente bloqueados en 1560 merced al papel adquirido por la joven congregación del Santo Oficio. En su acción represiva hacia los movimientos considerados heréticos, la congregación miró con sospecha a los nuevos cultos que nacían y que no parecían estar en sintonía con el espíritu de restauración que se estaba consolidando. Fue precisamente el procedimiento inquisitorial el que truncó la fama de santidad de la cual gozaban Paola Antonia Negri y el franciscano Matteo da Bascio ${ }^{11}$. La proclama tridentina a favor de la santidad, sin embargo, no permitía que la materia de canonización fuese confiada a una estructura meramente represiva, que, por otra parte, no estaba difundida en los otros países católicos. Con la reorganización de las congregaciones como consecuencia de la reforma de Sixto V, nació la Sagrada Congregación de Ritos que obtuvo la presidencia de los procesos de canonización.

\section{LA SAGRADA CONGREGACIÓN DE RITOS}

Sixto V con la constitución Immensa aeterni Dei del 22 de enero de 1588 fundó la Sagrada Congregación de Ritos, que nacía en el ámbito del nuevo reajuste perseguido por el papado en una visión mucho más centralizadora del gobierno de la Iglesia, que habría alcanzo el máximo esfuerzo en los años del pontificado de Clemente VIII (1592-1606) ${ }^{12}$. Cinco cardenales debían ocuparse de los ritos que tenían lugar con ocasión de la santa Misa, de los oficios divinos, de revisar los libros litúrgicos y los oficios para el santo patrón, como también de las canonizaciones de los santos y de sus fiestas. Caía dentro de las competencias de la Congregación resolver las controversias relativas al ceremonial pontificio con ocasión de las visitas de embajadores o de otros huéspedes de consideración en la Santa Sede.

Con la Congregación de Ritos nació un organismo centralizado romano, entre cuyas características destacaba la lentitud como signo de prudencia en la toma de decisiones. En esta Congregación se formó un personal cualificado en la selección de los santos. La canonización, se convirtió, sobre todo en el siglo XVII, en una operación jurídica más compleja y burocratizada, donde el factor tiempo

11 Miguel Gotor, Chiesa e santità nell'Italia moderna, Roma-Bari, 2004, pp. 26-28.

12 Véase a este propósito la obra de Niccolò DEL RE, La Curia romana. Lineamenti storico-giuridici, Roma 1970; Giampiero CAROCCI, Lo stato della chiesa nella seconda metà del sec. XVI. Note e contributi, Milano, 1961. 
asumió un papel determinante para no tomar decisiones precipitadas ${ }^{13}$. Por otra parte, numerosos teólogos romanos en la segunda mitad del siglo XVI habían afirmado la infalibilidad de los pontífices, cuando éstos proclamaban una canonización. Por este motivo, el procedimiento debía desarrollarse sobre unas bases sólidas y ciertas ${ }^{14}$. Los pontífices, por otra parte, se habían vuelto cautos para dar un consentimiento favorable a una causa de canonización. Durante el pontificado de Clemente VIII, por ejemplo, aun cuando Ignacio de Loyola, Carlos Borromeo y Felipe Neri gozaran de una amplia veneración, se prohibió la exposición de sus imágenes, aunque se producían milagros por su intercesión. Los mismos procesos del Borromeo, de Felipe Neri y de Francisca Romana fueron postergados con el fin de conseguir más pruebas ${ }^{15}$, y el pontificado quedó marcado por sólo dos canonizaciones celebradas en 1594 cuando fueron elevados a los altares el dominico Jacinto Odrowaz y Raimundo de Peñafort ${ }^{16}$. Igualmente, se mostró prudente Pablo V, que quiso canonizar únicamente a Francisca Romana y a Carlos Borromeo.

Cabe precisar que la congregación no conquistó inmediatamente la exclusiva en materia de beatificaciones y canonizaciones. $\mathrm{Al}$ menos hasta los años treinta del siglo XVII fue el Santo Oficio el que se ocupaba de la aprobación del culto público y de la represión de los abusos. Clemente VIII, para hacer frente a la petición de canonizaciones, instituyó la Congregación de Ritos que se reunió por primera vez en noviembre de $1602^{17}$. Solo con Urbano VIII la Congregación de Ritos tuvo plena soberanía en materia de canonizaciones ${ }^{18}$. Los dos dicasterios permanecieron, sin embargo, unidos por el asesor del Santo Oficio que inter-

13 El primer manual sobre la canonización, escrito después de la fundación de la Sagrada Congregación de Ritos, insiste sobre la necesidad del espaciamiento temporal para su constatación, como garantía de una atenta evaluación de la santidad de los siervos de Dios. Cfr. Angelo RocCA, De canonizatione sanctorum commentarius, Romae, 1601, pp. 69-70.

14 Cfr. Delumeau, La sainteté, cit., pp. 26-7. Entre los textos que apoyaban la infalibilidad del pontífice se cuenta el manual Angelo Rocca. Cfr. RocCA, De canonizatione, cit., pp. 93-119.

15 Cfr. Ludwig Von Pastor, Storia dei Papi, vol. XI, Roma,1942, pp. 489-90.

16 Cfr. Index ac status causarum, Città del Vaticano, 1988, p. 397. Estas canonizaciones estuvieron precedidas de la de Diego de Alcalá, celebrada el 2 de julio de 1588, antes de la fundación de la Congregación de Ritos. Sobre la canonización de Alcalá, véase Thomas James DANDELET, «Celestiali eroi» e lo «splendor d'Iberia». La canonizzazione dei santi spagnoli a Roma nell'età moderna, en Giovanna FIUME (ed.), Il santo patrono e la città. San benedetto il Moro: culti, devozioni strategie di età moderna, Venezia, 2000, pp. 183-197.

17 Cfr. Miguel GoTOR, I beati del papa. Santità, Inquisizione e obbedienza in età moderna, Firenze, 2002, pp. 127-134.

18 Giovanni PAPA, Le cause di canonizzazione del primo periodo della Congregazione dei Riti (1588-1634), Città del Vaticano, 2001. 
venía en los procesos de la Congregación de Ritos en el caso de que emergieran problemas relativos a una posible fingida santidad. Los dos ordenamientos, por otra parte, fueron juntados por el hecho de ser constituidos ambos en tribunal, con su consecuente potestad jurídica ${ }^{19}$.

Los primeros tiempos de la Sagrada Congregación de Ritos estuvieron caracterizados por la incertidumbre y la duplicación de competencias y solo después de algunos decenios se formó un personal bien preparado y se fueron definiendo con claridad sus funciones. En paralelo, tomó cuerpo, con bastante lentitud, la estructura definitiva de un proceso de canonización.

Por lo que respecta a la forma de los procesos, la Congregación de Ritos heredaba en realidad una estructura que ya había sido ampliamente alabada en la época tardo medieval. En aquella época, como ya se ha aludido, los obispos, bajo la presión de los religiosos y laicos, empezaron a realizar una investigación conducente a demostrar la subsistencia de la santidad en una persona. Estas investigaciones medievales, cuanto más lejanas en el tiempo, más se centraban en la comprobación de los milagros. Sólo con el acercarse a los últimos siglos medievales, se amplió el espacio dedicado a la comprobación de los comportamientos virtuosos de los canonizables. Los interrogatorios de los testimonios eran enviados a Roma, donde el pontífice, en el caso de que encontrara elementos válidos para una posterior profundización, nombraba a tres comisarios delegados que procedían a instruir un ulterior proceso in loco. Terminada la nueva investigación, la documentación era nuevamente transmitida a Roma, donde se daba inicio al procedimiento apostólico, que sería perfeccionado sobre todo en el curso de la edad moderna con la institución de la Congregación de Ritos con su personal especializado.

\section{EL PROCESO DE CANONIZACIÓN ENTRE «PERIFERIAS» DIOCESANAS Y «CENTRO» ROMANO}

En la edad moderna, una causa de beatificación y de canonización implicaba varios procesos y se distinguían dos fases: la primera se desarrollaba delante del tribunal del Ordinario diocesano, en la localidad en la cual el siervo de Dios había mayormente desarrollado su vida y donde su fama de santidad había surgido y se

19 Cfr. Giuseppe DALla TORRE, Santità ed economia processuale. L'esperienza giuridica da Urbano VIII a Benedetto XIV, en Gabriela ZARRI (ed.), Finzione e santità tra Medioevo ed Età moderna, Torino, 1991, pp. 246-248. 
había difundido, mientras que la segunda era competencia del pontífice y tenía lugar en la Sagrada Congregación de Ritos ${ }^{20}$. Al ordinario le tocaba desarrollar el importante proceso informativo super fama sanctitatis, martyrii et miraculorum y la investigación sobre los escritos de los siervos de Dios ${ }^{21}$. Con los decretos urbanianos se introdujo el proceso super non cultu.

El inicio del proceso estaba determinado por el hecho de que un postulador, apoyado por un grupo de devotos, pedía al obispo abrir una investigación sobre la base de las noticias difundidas sobre la fama de santidad y de milagros de un siervo o de una sierva de Dios difunta. No hay que olvidar que el proceso de canonización era un procedimiento «a favor» del candidato, con el objeto de presentar las pruebas de su santidad. El proceso empezaba, por lo tanto, con un cuestionario y una lista de testigos presentados al postulador ${ }^{22}$. Los testigos sufrían luego un contrainterrogatorio en base a las interrogationes formuladas por el abogado fiscal de la curia diocesana, figura más tarde sustituida por el promotor

20 Se recuerda que la beatificación es un acto del pontífice que permite tributar un culto público a un siervo de Dios exclusivamente en un lugar determinado, ya sea en una familia religiosas o en una región. La canonización, sin embargo, es la sentencia definitiva de un pontífice que declara que un siervo de Dios goza de la gloria eterna y ordena que se le tribute un culto público. Cfr. Raul NAZ, Causes de Beatification et de Canonisation, en Dictionnaire de droit Canon, Paris, 1942, vol. III, p. 10 .

21 He dicho que los procesos del Ordinario suponen una fuente importante para la historia de la santidad, aunque jurídicamente se trate de un proceso llevado por una autoridad inferior respecto a la apostólica. La investigación instruida por la autoridad episcopal era generalmente abierta poco después de la muerte del siervo de Dios, de tal modo que se podía recoger un mayor número de testimonios de visu, cosa que, por motivos obvios, con el pasar de los años, resultaba más difícil. A los procesos ordinarios super fama participaban, por otra parte, muchos más testigos de cuanto lo hacían en el proceso apostólico. Aun cuando la investigación llevada a cabo por la autoridad ordinaria tuviera formalmente una finalidad limitada en el conjunto de la causa de canonización, porque se desarrollaba en un estadio preliminar a la verdadera y propia instrucción de la causa, que era la del proceso apostólico, sin embargo, era más rica en testimonios e informaciones relativas a los siervos de Dios. El carácter subalterno de los procesos ordinarios, se coloca, por lo tanto, más en el ámbito formal y jurídico que en el de su valor como fuente histórica. Para todo esto, véase Giulio SodANO, Modelli e selezione del santo moderno. Periferia napoletana e centro romano, Napoli, 2002.

22 Para dar una mayor garantía de independencia del proceso respecto a la iniciativa del postulado, Inocencio XI en 1675 introdujo los testigos ex-officio. Cfr. Giovanni LOW, Canonizzazione, en Enciclopedia cattolica, vol. III, Firenze, 1949, p. 595. Debían ser al menos dos y eran convocados por el promotor de la fe o por el presidente del tribunal. Cfr. NAZ, Causes, cit., col. 19. Aunque su función era la de garantizar la veracidad de los hechos, la impresión que se saca de la lectura de los procesos de canonización es que su nombramiento era más formal que sustancial. De hecho, parece evidente que los nombres de los testigos ex-officio eran facilitados frecuentemente por el procurador de la causa al postulador. A menudo, eran conocidos del canonizable. Sobre este particular, véase SODANO, Modelli e selezione, cit., p. 52. 
de la fe. Los tiempos largos que imponía la causa, así como los costes exorbitados tanto en la periferia como en la curia romana ${ }^{23}$, requerían esfuerzos enormes que difícilmente podían ser soportados por grupos de laicos que con dificultad podían constituirse, de un modo duradero y autónomo, para un proyecto que habría implicado a varias generaciones. Por esto, la gran mayoría de causas estaban impulsadas por instituciones, como las órdenes religiosas.

Como en la época medieval, después de los procesos llevados a cabo por la autoridad episcopal, la causa proseguía «in periferia», pero dependiente de la autoridad pontificia. La fase «al centro», es decir, interna a la Sagrada Congregación de Ritos se iniciaba después del desarrollo de los procesos instruidos por la autoridad episcopal, con la Signatio Commissionis introductioni causae. Una vez introducida la causa en la Congregación de los Ritos, Roma nombraba nuevos jueces locales con litterae remissoriales y la redacción de las interrogationes por parte del promotor generalis fidei. Tenía lugar, pues, el inicio del doble proceso apostólico, del cual el primero se ocupaba de la fama sanctitatis y el segundo de las virtudes y los milagros in specie $e^{24}$. La parte apostólica del proceso con los interrogatorios de los testigos locales en realidad era muy parecida a la precedente. Por lo general, se escuchaban a los testigos del precedente proceso ordinario, si estaban vivos, con el añadido de alguno nuevo que deponía, sobre todo, sobre la persistencia de la fama sanctitatis. Con la conclusión de las dos encuestas apostólicas, terminaban los interrogatorios de los testigos y la fase «periférica» de la causa y se ponía en marcha la larga y compleja fase curial. La Congregación de los Ritos, después de haber despejado las dudas relativas a la validez jurídica de los procesos apostólicos, iniciaba el procedimiento relativo al reconocimiento de las virtudes en grado heroico, que, a partir de los decretos de Urbano VIII, podía desarrollarse 50 años después de la muerte del siervo de Dios ${ }^{25}$.

En muchos aspectos, como hemos visto, el proceso moderno tenía bastantes puntos en común con el tardo medieval, como el partir de la doble fase episcopal y apostólica. Sin embargo, las novedades procesuales de la edad moderna fueron notables. A parte de la complejidad de las fases procesuales, las novedades «modernas», a mi juicio, que influyeron fuertemente los contenidos del proceso son

23 Sobre los costes de una causa de canonización se puede consultar, a título de ejemplo, el caso estudiado por Marcella CAMPANELLI, Monasteri di provincia (Capua secoli XVI-XIX), Milano, 2012, pp. 174-177.

24 No siempre el proceso apostólico era doble, porque, si se juzgaba oportuno, no se desarrollaba el sub fama sanctitatis in genere y se pasaba directamente a la investigación sobre las virtudes y los milagros in specie. Cfr. NAZ, Causes de Beatification, cit., p. 27.

25 Fabiano Veraja, La beatificazione. Storia problemi prospettive, Città del Vaticano, 1983, pp. 71-79. 
sobre todo dos: la introducción de la fórmula de las virtudes heroicas y los decretos urbanianos con el nacimiento del proceso sobre el no culto.

\section{LAS VIRTUDES HEROICAS}

Como ya se ha dicho, los procesos medievales consistían sobre todo en la redacción de un catálogo de milagros. Solo con el tiempo se introdujeron también elementos ligados a la práctica de las virtudes. Si se examina el proceso de canonización de Francisco de Paula, celebrado con la edad moderna ya iniciada, se nota que el peso del milagro es aún preponderante, con una atención limitada al aspecto de las virtudes ${ }^{26}$. Solo después de Trento, efectivamente, se puede notar que los procesos dedican un espacio creciente al análisis de las virtudes. En aquellos años los procesos de canonización tendían a poner en evidencia las multiplex excellentia vitae de los candidatos, es decir las gestas insignes que habían realizado en vida.

Como es conocido, el término «heroicidad de las virtudes» fue acuñado por los teólogos de Salamanca con motivo de la petición que el 2 de febrero de 1602 dirigieron a Clemente VII para la canonización de Teresa de Ávila y estaba dirigido a dar una respuesta a las indicaciones sobre la medida de aquellas excelentia virtutum $^{27}$. El grado heroico debía emerger de un natural y permanente comportamiento virtuoso, realizado con facilidad y sin ninguna afectación. Las virtudes centrales del proceso eran las teologales (fe, esperanza y caridad hacia Dios y hacia el prójimo) y las cardinales (prudencia, justicia, fortaleza y templanza). A estas virtudes tradicionales se les aparejaban las de la obediencia, pobreza y castidad.

26 Véase I codici autografi dei processi cosentino e turonese per la canonizzazione di S. Francesco di Paola (1512-1513), Roma, 1964. Se han celebrado numerosos congresos con ocasión del IV centenario de la muerte del santo. Para el reino de Nápoles, véase Francesco SENATORE (ed.), S. Francesco di Paola e l'Ordine dei Minimi nel Regno di Napoli (secoli XV-XVII), Napoli, 2008.

27 Cfr. Romeo DE MAIO, Riforme e miti nella Chiesa del Cinquecento, Napoli, 1973, p. 257. Véase también, Alberto RoYo MEjÍA, Evolución bistórica de la prueba de heroicidad de las virtudes en las causas de los Santos en los siglos anteriores a Benedicto XIV, en Archivo Teológico Granadino, LVI (1993), pp. 25-61. Queda dicho que André Vauchez se ha opuesto al origen renacentista y contrarreformista, reivindicando su origen en el siglo XIII. VAUCHEZ, La santità, cit., p. 535. El término, como advierte el estudioso francés, está ciertamente presente en los procesos de Catalina de Siena y de Pedro de Luxemburgo, pero su aparición esporádica y episódica no se puede parangonar con el uso masivo de la época de la contrarreforma, amén del gran desarrollo que los tratadistas hicieron sobre las virtudes heroicas y que tuvo su ápice con la obra de Próspero Lambertini. Sobre esto, véase SODANO, Modelli e selezione, cit., pp. 26-34. 
La historia del nacimiento y de la consolidación de las virtudes heroicas, a mi juicio, está aún por escribirse. Por un lado, seguramente, la heroicidad nacía de la exigencia, inquisitorial, de desenmascarar el crimen de fingida santidad ${ }^{28}$. Por otro lado, era consecuencia de la cultura humanística renacentista, que con Castiglione veía en el equilibrio de los modos de obrar, en el desdén que se oponía a la afectación, el cumplimiento de un perfecto comportamiento humano ${ }^{29}$.

El uso de las virtudes heroicas como medida de reconocimiento de la santidad se fue progresivamente afirmando. Entre el 1614 y el 1616 el término comenzó a ser usado en Roma por los auditores de la Rota ${ }^{30}$. Unos años después aparece utilizado en los procesos periféricos. En Nápoles, por ejemplo, en los años veinte, aun cuando los artículos procesuales no hicieran referencia explícita, el concepto de la heroicidad de virtudes se iba afirmando por boca de los testimonios más cultivados ${ }^{31}$. Entre los siglos XVII y XVIII, también gracias a los manuales de canonización ${ }^{32}$, la expresión heroicidad de las virtudes se hizo cada vez más frecuente, hasta el punto de sostenerse que los procesos de beatificación y canonización debían versar casi exclusivamente sobre la comprobación de la práctica heroica de las virtudes ${ }^{33}$. El reconocimiento o no de las virtudes heroicas, a juicio del que escribe, representó, de hecho, el verdadero juez entre las canonizaciones exitosas y las fallidas, y por este motivo, al volver la atención hacia el «centro», es necesario focalizar la atención sobre ellas, intentado comprender su significado concreto.

El reconocimiento de las virtudes en grado heroico de una canonizado se convierte en una operación compleja en la parte curial del proceso. Después de la verificación de la corrección del procedimiento, los resultados del proceso ordinario y del apostólico eran presentados a través de la redacción de las positiones, que, generalmente, estaban compuestas de cuatro partes: la informatio, el summarium, las animadversiones y la responsio a las animadversiones. En la informa-

28 Sobre la santidad fingida, reenvio al volumen de ZARRI (ed.), Finzione e santità, cit.

29 Giulio SODANO, Prudenza e santità nell'età moderna, en Cesare MOZZARELLI y Chiara CONTINISIO (eds.). Repubblica e virtù. Pensiero politico e Monarchia cattolica fra XVI e XVII secolo, Roma, 1995, pp. 151-176.

30 Cfr. Low, Canonizzazione, cit., p. 596.

31 Se hace referencia al proceso de Jeremías de Valaquia donde el padre capuchino Severino hizo una referencia explícita, muy probablemente el primero en Nápoles, sobre las virtudes heroicas del lego capuchino. Cfr. SODANO, Modelli e selezione, cit., p. 50.

32 Ibid., pp. 26-34.

33 Cfr. Antoine De Bonhomme, Heroicité des vertus, en Dictionnaire de spiritualité ascétique et mystique, vol 7, col. 337-343, Paris, 1969. 
tio los postuladores de la causa resumían los aspectos relevantes de la santidad del siervo de la sierva de Dios. En el summarium se presentaban fragmentos de los testimonios referentes a cada una de las virtudes. Las deposiciones eran extraídas del proceso y encasilladas en los diferentes capítulos en los que estaba dividido el summarium como prueba de cada una de las virtudes. El promotor general de la fe, apodado, por sus funciones, el abogado del diablo, en la animadversio muestra sus propias dudas acerca del ejercicio de las virtudes heroicas de parte del venerable. Hay que tener en cuenta que los promotores indagaban entre todas las deposiciones escritas en los summaria. Si, por ejemplo, examinaban la virtud de la esperanza, no se contentaban con los testimonios encuadrados bajo aquella voz, sino que dirigían su atención también a otras partes del summarium. Esto comportaba una serie de consecuencias. Sucedía, de hecho, que algunos aspectos presentados en los summaria a favor de una determinada virtud, eran después utilizados por los promotores de la fe para mostrar errores de comportamiento en otras virtudes. Un «exceso» de abstinencia podía, por ejemplo, representar una falta de prudencia, porque se podía poner en peligro la propia salud ${ }^{34}$.

Todas las dudas expresadas por el promotor eran contestadas por el abogado defensor con la responsio. Las animadversiones del siglo XVII eran aún bastante simples, con pocos argumentos y un número reducido de objeciones, pero en el curso del tiempo asumieron una dimensión y complejidad relevante. Sobre todo, en el siglo XVIII primero y, también, después del ejercicio de promotor de la fe de Próspero Lambertini, entre el 1712 y el $1728^{35}$, las animadversiones aparecen complejas, articuladas, con numerosas referencias estructurales, teológicas y eruditas. Llama la atención la densidad de las argumentaciones esgrimidas por los promotores, que daban salida a una amplia cultura erudita que permitía presentar objeciones desde distintos puntos de vista. Solo al final del siglo XVIII y con el siglo XIX, las animadversiones volvieron a una forma más simple, casi como reacción al excesivo formalismo de gran parte del siglo.

La discusión sobre la heroicidad de las virtudes se desarrollaba a lo largo de tres congregaciones: la antepreparatoria, presidida por el cardenal ponente, con la participación del cardenal relator, de los consultores, del promotor y de los postuladores; la preparatoria, con la intervención de todos los cardenales de la

34 Sobre todos estos ejemplos, véase SodANO, Modelli e selezione, cit., pp. 237-265.

35 Sobre la figura de Próspero Lambertini se remite a Mario RoSA, Riformatori e ribelli nel '700 italiano, Bari, 1969 p. 52 e ss. Véase también, IDEM, Settecento religioso. Politica della Ragione e religione del cuore, Venezia, 1999. 
Congregación; la general, con la presencia del pontífice ${ }^{36}$. La congregación general y la preparatoria estaban presentes en el procedimiento para la beatificación de los decretos de Urbano VIII de $1634^{37}$. La institución de la antepreparatoria se consolidó, sin embargo, alrededor del $1690^{38}$.

El fin de la congregación antepreparatoria era informar al cardenal ponente, y el de la preparatoria era informar a los cardenales de la congregación sobre el estado de la causa. En estas dos ocasiones los cardenales escuchaban el parecer de los consultores. En la tercera congregación los cardenales votaban ${ }^{39}$. El voto era solo consultivo y la decisión última era del papa que, aun habiendo resuelto las dudas en sentido favorable a las tesis del defensor de la causa, hacia emanar un decreto con el que se declaraba formalmente que el siervo o la sierva de Dios había manifestado en su vida el ejercicio de las virtudes en grado heroico.

El acto pontificio de la proclamación del ejercicio de las virtudes en grado heroico de un siervo de Dios asumió tal importancia que entorno a él se desarrolló un preciso ceremonial. Con Clemente XI entró en uso que el papa, antes de tomar una decisión, reflexionase por algunos días recogido en oración. Con Benedicto XIV, el decreto era fijado en las puertas de todas las iglesias de Roma y, en la segunda mitad del siglo XVIII, los actos fueron formulados siempre gradualmente de modo más solemne. Solo después de ese paso se podía poner en marcha el proceso sobre los milagros y, comprobada su autenticidad a través de un complejo procedimiento parecido al requerido para la aprobación de las virtudes, se podía proceder a la ceremonia de beatificación. Si después, sucesivamente, aparecían nuevos milagros, el postulador de la causa podía pedir la apertura de un nuevo proceso, para comprobar la autenticidad de al menos dos de ellos. Terminado el proceso, se desarrollaban tres consistorios, en el último de los cuáles el pontífice, si había sido favorable, firmaba el decreto de canonización.

Hemos recorrido, en sus líneas esenciales, las fases de una causa de canonización para subrayar como con la edad moderna la constatación de las virtudes en grado heroico constituye la condición indispensable para conferir el título de beato y que por lo tanto se abriese la vía para la canonización. A través del análisis de esa heroicidad la Sagrada Congregación de Ritos y los promotores de la fe «se-

36 Para la congregación preparatoria y para la general se escribían otras positiones con el título de nova positio para la primera, y novissima para la última.

37 Cfr. VERAJA, La beatificazione, cit., p.74.

38 Cfr. Giovanni PAPA, Una complessa causa di beatificazione: il beato Paolo Burali d'Arezzo, Roma,1978, pp. 81-83.

39 Cfr. ibid., p. 84. 
leccionaban» a los siervos de Dios candidatos a los altares. Por poner un ejemplo, en el curso del siglo XVIII fue a través de las animadversiones que se bloquearon propuestas de santidad de sabor fuertemente místico que, casi contemporáneas al proceso a los quietistas, no estaban en sintonía con el modelo ascético que se imponía con fuerza ${ }^{40}$.

Todo esto, sin embargo, no significaba que la investigación estuviese exclusivamente dirigida a la comprobación de las virtudes. En los procesos de canonización napolitanos, que fueron verdaderamente numerosos en el curso de la edad moderna, los procesos en la periferia tal como estaban organizados por los procuradores de la causa preveían que los religiosos, más dotados culturalmente, depusieran sobre las virtudes, mientras que los laicos eran convocados esencialmente para testimoniar sobre los sucesos milagrosos ${ }^{41}$. Es muy probable que esta situación estuviera muy difundida entre las diócesis, desarrollando un verdadero y propio método de conducción de las causas de canonización.

\section{LOS DECRETOS DE URBANO VIII}

El estrecho filtro del reconocimiento de las virtudes heroicas proporcionó a la Iglesia el modo de ejercer una fuerte selección en los modelos de santidad. Pero otros mecanismos de selección fueron tomando forma a través de las estructuras procedimentales, con los decretos de Urbano VIII, publicados en 1642, precedidos del breve Caelestis ferusalem cives del $1625^{42}$.

Las disposiciones del papa Barberini precisaban los requisitos para la introducción de la causa: la ausencia de un culto indebido atribuido al candidato; la pureza de la doctrina del siervo de Dios, avalada a partir del proceso sobre sus escritos $^{43}$; la existencia de una legítima fama de santidad y milagros ${ }^{44}$. El proceso super non cultu fue instituido para constatar si había sido dispensado al venerable de quien se pretendía obtener la beatificación un culto público. Se entendía por culto público el celebrado en nombre de la Iglesia por personas habitualmente encargadas de ejercer el culto, o la exposición de estatuas, imágenes o reliquias en

40 Sobre este punto se reenvía a SODANO, Modelli e selezione, cit., pp. 105-135.

41 Se vea sobre este particular, ibid.

42 Sobre los decretos barberinos, cfr. VERAJA, La beatificazione, pp. 71-79.

43 Sobre el proceso acerca de los escritos, véase, Francesco LEONE, La prova documentale degli scritti nei processi di Beatificazione e Canonizzazione, Roma, 1989, pp. 25-42.

44 Cfr. Dalla TORRE, Santità, cit., p. 235. 
lugares públicos de oración ${ }^{45}$. Se ha afirmado que la idea del proceso sub non cultu marca la cesura entre la edad medieval y la moderna desde el punto de vista de la historia de la santidad, porque desde este momento el culto a un santo podía nacer sólo después de la aprobación de la jerarquía eclesiástica. La introducción de la praxis de que se pudiera discutir sobre las virtudes heroicas solo cincuenta años después de la muerte del siervo de Dios ${ }^{46}$, así como la reducción de las reuniones anuales de la congregación de 15 a $3^{47}$ provocó una ralentización considerable de los trabajos, como una prueba de que el factor tiempo era una de las mejores garantías para una decisión ponderada en materia de santidad.

Como hemos tenido ocasión de decir desde el principio, la reserva del pontífice tiene un origen medieval, porque ya desde esa época se veía necesario, para atribuir el título de santo, el beneplácito del pontífice. Sin embargo, es verdad que, al lado de esta santidad romana, seguía existiendo una santidad local, con el culto de los beatos. Con los decretos urbanianos, la congregación proponía al pontífice la Signatura commissionis introductionis causae, después de haber comprobado la fama de santidad, la ausencia de errores en sus escritos y la ausencia de un culto indebido, sobre la base de los procesos desarrollados por la autoridad diocesana. Este procedimiento representó el instrumento técnico-jurídico que hizo posible la definitiva afirmación jurídico-institucional de la Sagrada Congregación de Ritos, con la expropiación a la autoridad episcopal de los poderes jurisdiccionales sobre la causa de los santos ${ }^{48}$. Desde este punto de vista, la edad post tridentina marca un verdadero cambio, porque cesó la existencia de esta santidad menor local, para dar vida a una única santidad, reconocida exclusivamente por las máximas jerarquías romanas. En este hecho, se puede reconocer el fin de la vox populi, vox Dei, a favor de una exclusiva voz oficial proveniente de Roma, que veía en determinados personajes unas características que los hacían dignos de ser elevados a los altares y, sobre todo, de proponerlos a la admiración e imitación por parte de los fieles de toda la catolicidad. Es evidente que las canonizaciones debían sustentarse en criterios universalmente válidos. Esto quería decir que, a partir de este momento, la santidad tiene un valor universal y poco tenía que

45 NAZ, Causes de Beatification, cit., p. 22.

46 Cfr. VERAJA, La beatificazione, cit., p. 71-79. RoYo MEJÍA, Evolución bistórica, cit., p. 56

47 La decisión fue promulgada por la Sagrada Congregación de Ritos en el 1630. Cfr. DITCHFIELD, How not to be, cit., p. 399.

48 Dalla TORRE, Santità, cit., p. 248. Sobre el De Signatura commissionis in causis in materia di non cultus después de los decretos urbanianos, cfr. Prospero LAMBERTini, De Servorum Dei Beatificatione et Beatorum canonizatione, tomo II, Romae, 1748, pp. 432-446. 
ver con las exigencias e inclinaciones locales. La transformación, siempre por obra y gracia del papa Barberini, de la figura del abogado fiscal que controlaba el correcto desarrollo del procedimiento, en el promotor de la fe ${ }^{49}$, que se encargaba de la consistencia del conjunto de las pruebas de santidad, creaba una figura fundamental para que el «centro» pudiera juzgar lo que venía afirmado por la «periferia» con el fin de seleccionar los modelos de santidad.

\section{EL PROCESO COMO SELECCIÓN DE LOS MODELOS DE SANTIDAD}

Las causas de canonización tal como se fueron estructurando después del nacimiento de la Congregación de Ritos y las reformas de Urbano VIII no fueron exclusivamente una máquina jurídica neutral de comprobación de los hechos, sino un potente instrumento a través del cual la Iglesia seleccionó a los campeones de la fe idóneos para el diseño de un universalismo católico a la vez que bloqueó propuestas que no se consideraban en sintonía con los procesos contrarreformistas. El proceso histórico de las causas de canonización evidencia una especie de heterogénesis de los fines: nacido de la exigencia de las comunidades y de sus obispos para dar lustre a las canonizaciones locales, condujo a la reserva papal sobre toda la materia; de acto conclusivo de un movimiento nacido de la base, se convirtió en un instrumento de control de la Iglesia. Esta progresiva centralización, que alcanzó su culmen entre los siglos XVII y XVIII, ha hecho que las causas de canonización sean un instrumento contra la proliferación de los cultos cívicos y dinásticos que habían caracterizado la santidad durante la Edad media y que podían alimentar una visión peligrosamente privatizada de la santidad. También, durante el siglo XVII, llegaron de la periferia de la catolicidad peticiones de canonización de soberanos o de exponentes de las casas reales o apoyadas por las dinastías en busca de una sacralización del poder regio. Los decretos de Urbano VIII tuvieron como finalidad el bloqueo de estas peticiones, por temor a una instrumentalización política de la santidad ${ }^{50}$. La afirmación definitiva del primado pontificio en materia de canonización despojaba, por otra parte, también a los obispos de los restos de autonomía

49 El Promotor de la fe fue instituido por Urbano VIII con el breve del 11 de enero de 1631. Cfr. PAPA, Una complessa causa, cit., p. 50. Precedentemente, su papel lo hacía el procurador general del fisco. Véase, también, RoYO MEJÍA, Evolución bistórica, cit., p. 56.

50 Marina Caffiero, Santità, politica, e sistemi di potere, en Sofia Boesch Gajano (ed.), Santità, culti, agiografia. Temi e prospettive, Roma, 1997, p. 368. 
que les quedaban en materias de santidad. Fue este uno de los tantos modos a través de los cuales Roma se opuso a los numerosos movimientos tendentes a afirmar la autonomía de las iglesias locales de la autoridad pontificia, que entre el siglo XVII y XVIII, gracias sobre todo al jansenismo y al galicanismo, se hacían sentir con fuerza ${ }^{51}$.

Al lado de estas funciones internas en la Iglesia, había otra de gran relieve: el trabajo desarrollado por la Sagrada Congregación de Ritos filtraba, a través de los modelos heroicos de virtud, los comportamientos morales. Los promotores de la fe, en su actividad, estaban particularmente atentos a verificar la «medida» de los grados de virtud ejercitadas por los canonizables. Con la completa afirmación del sistema de la heroicidad de virtudes este método de investigación mutó profundamente. Los promotores de la fe cambiaron la perspectiva y se dirigieron sobre todo a individuar más propiamente los «errores» cometidos por los siervos de Dios en su actuar ${ }^{52}$. Pero en esta investigación de los errores de los comportamientos en el banco de los acusados, más allá de los canonizables, eran juzgados todos aquellos que en las «periferias» sostenían que estos comportamientos debían ser considerados como virtuosos. Se determinaba, por lo tanto, una sustancial devaluación de todas las interpretaciones y lecturas de la santidad desarrolladas en la periferia, ya fuere por parte de las órdenes religiosas como por parte de los laicos. Todo lo que era considerado un signo de santidad en la periferia venía nuevamente interpretado desde Roma hasta darle un significado en ocasiones opuesto. La actitud prevalente de los promotores de la fe fue de rebajamiento de las certificaciones sobre la santidad, pero también de las interpretaciones de los comportamientos virtuosos de los siervos de Dios por parte de los testimonios locales y de los procuradores de las causas, una devaluación, por lo tanto, de todas las interpretaciones periféricas de los hechos de fe y de la capacidad de poder distinguir una verdadera acción virtuosa de una aparente. La periferia era juzgada como incapaz de discernir una acción virtuosa de una errónea. Esta capacidad debía pertenecer, en cambio, únicamente a Roma. El centro de la catolicidad se erguía como juez único de los «comportamientos virtuosos» de la santidad y, a través de ellos, de los comportamientos de los fieles en general.

51 Claudio DonATI, La Chiesa di Roma tra Antico Regime e riforme settecentesche, en Giorgio CHITTOLINI y Giovanni MiCCOLI (eds.), Annali della Storia d'Italia, vol. IX, La Chiesa e il potere politico, a cura di Torino, 1986, p. 747.

52 SODANO, Modelli e selezione, cit., pp. 237-265. 


\section{EL NUEVO PROCESO DE CANONIZACIÓN DE LA EDAD MODERNA}

\section{REFERENCIAS BIBLIOGRÁFICAS}

CAFFIERO, Marina, Santità, politica, e sistemi di potere, en Sofia BoEsCH GajanO (ed.), Santità, culti, agiografia. Temi e prospettive, Roma, 1997.

CAMPANELlI, Marcella, Monasteri di provincia (Capua secoli XVI-XIX), Milano, 2012.

CAROCCI, Giampiero, Lo stato della chiesa nella seconda metà del sec. XVI. Note e contributi, Milano, 1961.

Dalla TORRE, Giuseppe, Processo canonico (processo di beatificazione e canonizzazione), en Enciclopedia del diritto, Milano, 1987, pp. 932-943.

- Santità ed economia processuale. L'esperienza giuridica da Urbano VIII a Benedetto XIV, en Gabriela ZARRI (ed.), Finzione e santità tra Medioevo ed Età moderna, Torino, 1991, pp. 231-263.

DANDELET, Thomas James, «Celestiali eroi» e lo «splendor d'Iberia». La canonizzazione dei santi spagnoli a Roma nell'età moderna, en Giovanna FIUME (ed.), Il santo patrono e la città. San benedetto il Moro: culti, devozioni strategie di età moderna, Venezia, 2000, pp. 183-197.

DE BONHOMme, Antoine, Heroicité des vertus, en Dictionnaire de spiritualité ascétique et mystique, vol 7, Paris, 1969, coll. 337-343.

DEL RE, Niccolò, La Curia romana. Lineamenti storico-giuridici, Roma, 1970.

DELUMEAU, Jean, La sainteté catolique, en Histoire des saints et de la sainteté chrétienne, vol. VIII, Paris, 1987, pp. 25-35.

— Rassurer et protéger. Le sentiment de sécurité dans l'Occident d'autrefois, Paris, 1989.

DE MAIO, Romeo, Riforme e miti nella Chiesa del Cinquecento, Napoli, 1973.

DITCHFIELD, Simon, How not to be a Counter-reformation saint: the attempted canonization of Pope Gregory X, 1622-1645, en Papers of the British School at Rome, LX (1992), pp. 379-422.

Donati, Claudio, La Chiesa di Roma tra Antico Regime e riforme settecentesche, en Giorgio ChitTolini y Giovanni Miccoli (eds.), Annali della Storia d'Italia, vol. IX, La Chiesa e il potere politico, Torino, 1986, p. 747.

GALASSO, Giuseppe, L'altra Europa. Per un'antropologia storica del Mezzogiorno d'Italia, Milano, 1982.

GOTOR, Miguel, I beati del papa. Santità, Inquisizione e obbedienza in età moderna, Firenze, 2002.

- Chiesa e santità nell'Italia moderna, Roma-Bari, 2004, pp. 26-28.

- I codici autografi dei processi cosentino e turonese per la canonizzazione di S, Francesco di Paola (1512-1513), Roma, 1964.

Index ac status causarum, Città del Vaticano, 1988.

KUTTNER, Stephan, La réserve papale du droit de canonisation, en Revue historique de droit français et étranger, XVIII (1938), pp. 172-228.

LAMBERTINI, Prospero, De Servorum Dei Beatificatione et Beatorum canonizatione, tomo II, Romae, 1748.

LÄMMER, Hugo, De Martyrologio Romano, Ratisbona, 1878.

LEONE, Francesco, La prova documentale degli scritti nei processi di Beatificazione e Canonizzazione, Roma, 1989.

Low, Giovanni, Canonizzazione, en Enciclopedia cattolica, vol. III, Firenze, 1949, pp. 569-607.

NAZ, Raul, Causes de Beatification et de Canonisation, en Dictionnaire de droit Canon, Paris, 1942, vol. III, pp. 10-37. 


\section{GIULIO SODANO}

Prosperi, Adriano, Intellettuali e Chiesa all'inizio dell'età moderna, en C. Vivanti (ed.), Annali della Storia d'Italia, vol. Iv, Intellettuali e Potere, Torino, 1981, pp.159-252.

- Il Concilio di Trento: una introduzione storica, Torino, Einaudi, 2001.

RoCCA, Angelo, De canonizatione sanctorum commentarius, Romae, 1601.

ROYO MEJÍA, Alberto, Evolución histórica de la prueba de heroicidad de las virtudes en las causas de los Santos en los siglos anteriores a Benedicto XIV, en Archivo Teológico Granadino, LVI (1993), pp. 25-61.

PAPA, GIOvanni, Una complessa causa di beatificazione: il beato Paolo Burali d'Arezzo, Roma, 1978.

Le cause di canonizzazione del primo periodo della Congregazione dei Riti (1588-1634), Città del Vaticano, 2001.

PASTOR vOn LudWIG, Storia dei Papi, vol. XI, Roma, 1942.

Rosa, Mario, Riformatori e ribelli nel '700 italiano, Bari, 1969.

- Settecento religioso. Politica della Ragione e religione del cuore, Venezia, 1999.

SARPI, Paolo, Istoria del concilio tridentino, ed. Sansoni, Firenze, 1966, vol. II.

SAlLmanN, Jean Michael, Santi barocchi: modelli di santità, pratiche devozionali e comportamenti religiosi nel Regno di Napoli dal 1540 al 1750, Lecce, 1996.

SENATORE, Francesco (ed.), S. Francesco di Paola e l'Ordine dei Minimi nel Regno di Napoli (secoli $X V$-XVII), Napoli, 2008.

SODANO, Giulio, Prudenza e santità nell'età moderna, en Cesare MOZZARELli y Chiara CoNTINISIO (eds.). Repubblica e virtù. Pensiero politico e Monarchia cattolica fra XVI e XVII secolo, Roma, 1995, pp. 151-176.

- Modelli e selezione del santo moderno. Periferia napoletana e centro romano, Napoli, 2002.

VAUCHEZ, André, La santità nel Medioevo, ed. it., Bologna, 1989.

VerajA, Fabiano, La beatificazione. Storia problemi prospettive, Città del Vaticano, 1983.

ZARrI, Gabriella, Le sante vive. Profezie di corte e devozione femminile tra '400 e "500, Torino, 1990. 